\title{
Aristolochic acid exposure in Romania and implications for renal cell carcinoma
}

\author{
Robert J Turesky*,1, Byeong Hwa Yun ${ }^{1}$, Paul Brennan², Dana Mates ${ }^{3}$, Viorel Jinga ${ }^{4}$, Patricia Harnden ${ }^{5}$, \\ Rosamonde E Banks ${ }^{5}$, Helene Blanche ${ }^{6}$, Marie-Therese Bihoreau ${ }^{7}$, Priscilia Chopard ${ }^{2}$, Louis Letourneau ${ }^{8}$, \\ G Mark Lathrop ${ }^{8}$ and Ghislaine Scelo*,2
}

\begin{abstract}
${ }^{1}$ Masonic Cancer Center and Department of Medicinal Chemistry, University of Minnesota, Minneapolis, MN 55455, USA; ${ }^{2}$ International Agency for Research on Cancer (IARC), 150 Cours Albert Thomas, Lyon 69008, France; ${ }^{3}$ National Institute of Public Health, 1-3 Doctor Leonte Anastasievici, Sector 5, Bucharest 050463, Romania; ${ }^{4}$ Carol Davila University of Medicine and Pharmacy, Th. Burghele Hospital, 20 Panduri Street, Bucharest 050659, Romania; ${ }^{5}$ Leeds Institute of Cancer and Pathology, University of Leeds, Cancer Research Building, St James's University Hospital, Leeds LS9 7TF, UK; ${ }^{6}$ Fondation Jean Dausset-Centre d'Etude du Polymorphisme Humain, 27 Rue Juliette Dodu, Paris 75010, France; ${ }^{7}$ Centre National de Genotypage, Institut de Genomique, Centre de l'Energie Atomique et aux Energies Alternatives, 2 Rue Gaston Cremieux, Evry 91000, France and ${ }^{8}$ McGill University and Genome Quebec Innovation Centre, 740 Doctor Penfield Avenue, Montreal, Quebec H3A OG1, Canada
\end{abstract}

Background: Aristolochic acid (AA) is a nephrotoxicant associated with AA nephropathy (AAN) and upper urothelial tract cancer (UUTC). Whole-genome sequences of 14 Romanian cases of renal cell carcinoma (RCC) recently exhibited mutational signatures consistent with AA exposure, although RCC had not been previously linked with AAN and AA exposure was previously reported only in localised rural areas.

Methods: We performed mass spectrometric measurements of the aristolactam (AL) DNA adduct 7-(deoxyadenosin- $N^{6}$-yl) aristolactam I (dA-AL-I) in nontumour renal tissues of the 14 Romanian RCC cases and 15 cases from 3 other countries.

Results: We detected dA-AL-I in the 14 Romanian cases at levels ranging from 0.7 to 27 adducts per $10^{8}$ DNA bases, in line with levels reported in Asian and Balkan populations exposed through herbal remedies or food contamination. The 15 cases from other countries were negative.

Interpretation: Although the source of exposure is uncertain and likely different in AAN regions than elsewhere, our results demonstrate that AA exposure in Romania exists outside localised AAN regions and provide further evidence implicating AA in RCC.

Aristolochic acid nephropathy (AAN) is characterised by chronic renal disease with slow progression to terminal renal failure, and transitional cell carcinoma of the upper urinary tract (UUTC) (Debelle et al, 2008). Under the name of 'Balkan Endemic Nephropathy' (BEN), it affects parts of Southeastern Europe including some Romanian villages located in the Danube river basin (Stefanovic and Polenakovic, 2009). Aristolochia clematitis is endemic in the region and chronic exposure to aristolochic acid (AA) probably originates from harvesting the herb together with wheat, hence contaminating home-made and locally produced flour ingested by the population (Stefanovic and Polenakovic, 2009). In Taiwan and other Asian countries, AA exposure is attributed to usage of traditional Chinese herbs containing Aristolochia (Debelle et al, 2008). The carcinogenic effect of AA in the upper urinary tract includes a unique signature of otherwise rare A:T> T:A transversions in the gene TP53 (Grollman et al, 2007; Chen et al, 2012) but also at the genome-wide level (Hoang et al, 2013; Poon et al, 2013). The mechanism involved in the carcinogenesis has been well described (Sidorenko et al, 2012; Grollman, 2013). The AA reactive intermediates bind covalently to

*Correspondence: Professor RJ Turesky; E-mail: rturesky@umn.edu or Dr G Scelo; E-mail: scelog@iarc.fr

Received 2 July 2015; revised 9 October 2015; accepted 19 October 2015;

published online 10 December 2015

(c) 2016 Cancer Research UK. All rights reserved 0007 - 0920/16

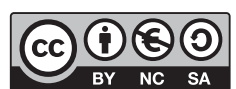


the DNA, creating bulky DNA lesions on the adenosine base: the deoxyadenosine DNA adducts 7-(deoxyadenosin- $\left.N^{6}-y l\right)$ aristolactam I (dA-AL-I) and 7-(deoxyadenosin- $N^{6}$-yl) aristolactam II (dA-AL-II) that partially block DNA replication and give rise to misincorporation of nucleotides (Attaluri et al, 2010).

Our recent whole-genome sequencing study of renal cell carcinomas (RCCs) revealed that the AA-induced typical mutational signature was very common in Romanian cases (12 out of 14 cases carried high rates of A:T $>\mathrm{T}:$ A transversions), and absent in 80 other cases diagnosed in the United Kingdom, Russian Federation, and Czech Republic (Scelo et al, 2014). Although AA is the only compound reported thus far to cause this mutation pattern, the finding triggered further investigations because (1) RCC was not known to be associated with exposure to AA; (2) nontumour renal cortices of the 14 Romanian cases did not show typical characteristics of chronic AA exposure, with no sign of dense interstitial fibrosis or tubular atrophy; and (3) the recruiting hospital was located in Bucharest although inhabitants of the BEN area are usually hospitalised in Timisoara or Craiova (two cities of the Western and Southwestern part of Romania; Figure 1).

We sought to determine whether the observed mutational $\mathrm{A}: \mathrm{T}>\mathrm{T}: \mathrm{A}$ profile was due to AA exposure by measurement of ALDNA adducts in the nontumour renal cortex DNA samples of the 14 Romanian cases and 15 cases from other countries. As AL-DNA adducts can persist for more than 20 years in the renal cortex (Schmeiser et al, 2014), we also investigated the residential history of the Romanian cases.

\section{MATERIALS AND METHODS}

Sample selection. Samples were selected for this study from among 94 cases who went through whole-genome sequencing as previously described (Scelo et al, 2014). All 14 Romanian cases were selected for this study, and 15 additional cases were randomly chosen among 80 cases from the United Kingdom, Russian
Federation, and Czech Republic (five cases in each country; Supplementary Table 1). Samples were analysed with the investigator blind to the country of origin of the samples. Written, informed consent was obtained from each participant and the study was approved by the relevant institutional review boards.

DNA isolation from nontumour renal tissue samples. Nontumour renal tissue samples were harvested immediately following nephrectomy for renal cancer. Tissue samples were snap frozen (Russia and United Kingdom) or preserved by immersion into RNAlater (AMBION, Inc., Austin, TX, USA) and frozen (Romania, Czech Republic). All samples were sectioned at IARC with subsequent pathological review undertaken in Leeds $(\mathrm{PH})$ to confirm the absence of tumour cells, and to evaluate the presence of tubules, glomerules, fibrosis, and inflammation (Scelo et al, 2014). Contiguous sections were also prepared for DNA isolation that was undertaken at $\mathrm{CEPH}$ following a semiautomated procedure on Autopure (Qiagen, Hilden, Germany) and with samples from Romania also having further DNA extracts prepared using a phenol/chloroform protocol at IARC. These additional DNA extractions were undertaken in order to directly compare DNA adduct levels with previous studies that used a phenol/ chloroform extraction protocol (Yun et al, 2015).

Enzymatic digestion of renal tissue DNA. DNA $(5 \mu \mathrm{g})$ was spiked with $\left[{ }^{15} \mathrm{~N}_{5}\right]$-dA-AL-I and $\left[{ }^{15} \mathrm{~N}_{3}\right]$-dA-AL-II, synthesised as previously described (Yun et al, 2012) at a level of 5 adducts per $10^{8}$ DNA bases and incubated with DNase I and nuclease P1 for $3.5 \mathrm{~h}$, followed by incubation with phosphodiesterase I and alkaline phosphatase for $18 \mathrm{~h}$ at $37^{\circ} \mathrm{C}$. The DNA digest was dried by vacuum centrifugation and reconstituted in $35 \mu \mathrm{l}$ of $1: 1 \mathrm{H}_{2} \mathrm{O} /$ DMSO. DNA quality and enzymatic digestion efficacy was assessed by HPLC-UV on 10 randomly selected samples ( 5 from Romania, 2 from Czech Republic, 2 from the United Kingdom, and 1 from Russia) (Yun et al, 2013). RNA contamination was $<2 \%$ and digestion efficiency of DNA went to completion for all samples.

Measurement of AL-DNA adducts by UPLC-ESI/MS ${ }^{3}$. Mass spectrometry was employed to quantify dA-AL-I and dA-AL-II by

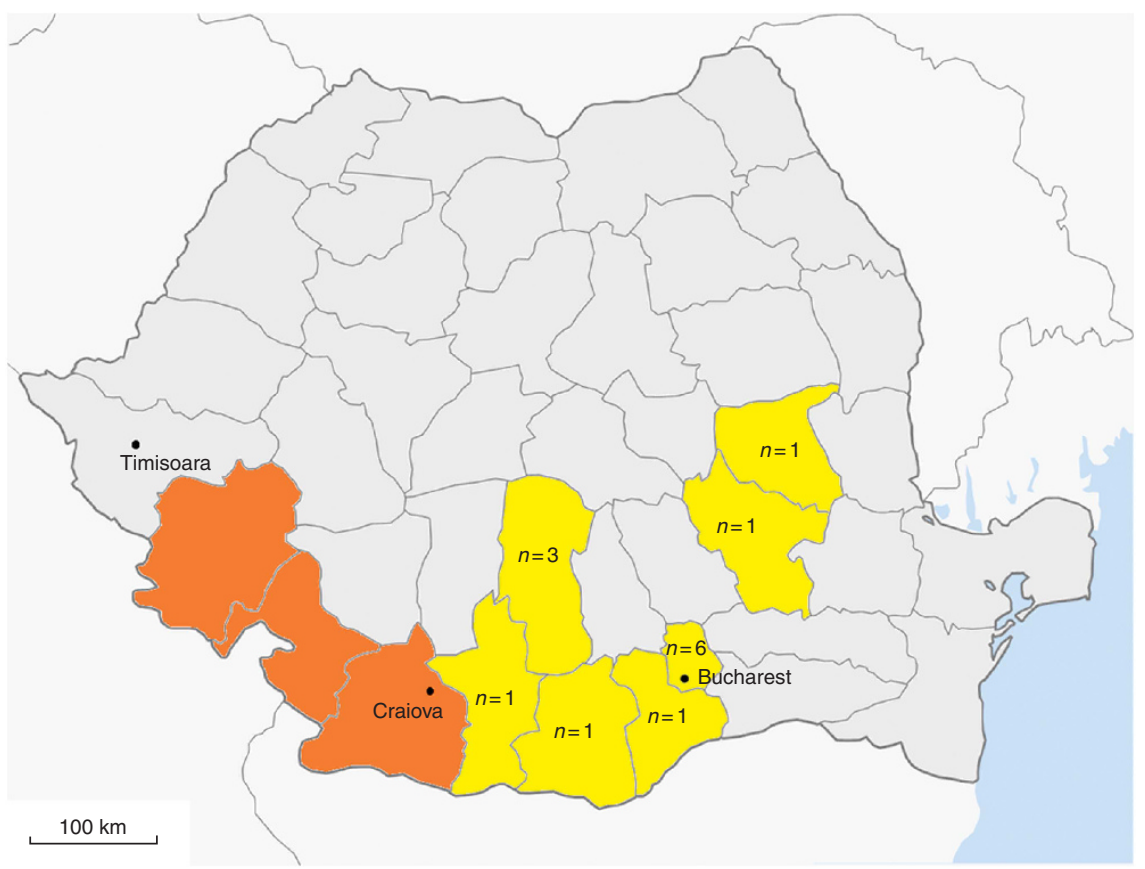

Figure 1. Map of Romania showing counties affected by the Balkan endemic nephropathy (BEN; orange shaded) and counties of residence of the 14 Romanian cases at the time of renal cell carcinoma diagnosis (yellow shaded). Number of cases in each county is indicated. Timisoara and Craiova are the two cities where inhabitants from the BEN area are usually hospitalised (modified from http://commons.wikimedia.org/wiki/ File:Romania_counties_blank_big.png). 
the stable isotopic dilution method (Yun et al, 2012, 2014) (Supplementary Figure 1). We used a NanoAcquity UPLC system (Waters Corporation, Milford, MA, USA) interfaced with an Advance CaptiveSpray source from Michrom Bioresource (Auburn, CA, USA) and an ion-trap mass spectrometer (LTQ Velos Pro; Thermo Fisher, San Jose, CA, USA). A Waters Symmetry C18 trap column $(180 \mu \mathrm{m} \times 20 \mathrm{~mm}, 5 \mu \mathrm{m}$ particle size $)$ was employed for online enrichment of the DNA adducts. A Magic C18 AQ column $(0.3 \times 150 \mathrm{~mm}, 3 \mu \mathrm{m}$ particle size; Michrom Bioresources) was used for chromatography. The DNA adducts were measured in the positive ionisation mode at the $\mathrm{MS}^{3}$ scan stage. The chromatographic and mass spectra acquisition parameters have been described previously (Yun et al, 2012, 2013).

Statistical analysis. We performed a Wilcoxon rank-sum test to compare the tumour A:T > T:A mutation loads using both the number and the proportion of A:T $>\mathrm{T}$ :A mutations in subjects with detectable vs subjects with undetectable adducts (available from Scelo et al, 2014, and reproduced in Supplementary Table 1). To analyse the correlation between the quantity of adducts and the proportion of A:T $>$ T:A mutations in tumours, we fitted a binomial model with a logistic link function of $\log (\mathrm{dA}-\mathrm{AL}-\mathrm{I}+1)$ on proportions of A:T $>\mathrm{T}: \mathrm{A}$ weighted by the number of total mutations (see Supplementary Notes). We calculated odds of A:T > T:A mutations $v s$ other mutation types (odds ratios (ORs)) for 1 $\log (\mathrm{dA}-\mathrm{AL}-\mathrm{I})$ increment and their $95 \%$ confidence intervals (95\% CIs).

Assessment of residential history in Romanian cases. County of residence at the time of RCC diagnosis was available for all 14 Romanian cases. Five cases were successfully recontacted and provided a full lifetime residential history. Since the 1980s, all Romanian citizens are allocated with a personal identification code that encodes the county of residence among other information. Before its use became systematic in the 1990s, this could be either the county of residence at the time of birth or the country of residence at the time when the code was allocated to the individual. Although there is no possibility to decipher between the two, we nevertheless used this information (available for 13 cases) in search for evidence that some cases may have lived in the BEN area at some point in their life.

\section{RESULTS}

In all 14 Romanian cases, dA-AL-I was detected in DNA samples obtained from the phenol/chloroform extraction method (range: $0.7-26.8$ adducts per $10^{8}$ DNA bases; Figure 2 and Supplementary Table 1) and below the limit of quantification ( 0.3 adducts per $10^{8}$ DNA bases) in all 15 non-Romanian cases. Only one Romanian sample was below the detection threshold when using DNA samples obtained from the Autopure extraction protocol. Thus, our data show that dA-AL-I is stable towards tissue storage in RNAlater and largely survives extensive DNA processing. Consistent with previous studies, dA-AL-II was below the limit of quantification in all subjects (Yun et al, 2015).

The load of A:T > T:A mutations in tumours was significantly higher in the 14 Romanian samples with detectable dA-AL-I than in the 15 other samples (Wilcoxon rank-sum test $P<10^{-5}$ when comparing both the numbers and the proportions of A:T > T:A mutations). Similar results were obtained when using the adduct quantities measured on the DNA samples obtained from the Autopure extraction method. The proportion of A:T > T:A mutations was positively associated with the log quantity of dA-AL-I adducts (odds of A:T > T:A mutations vs other mutation types increased by 2.09 for $1 \log (\mathrm{dA}-\mathrm{AL}-\mathrm{I})$ increment (95\% CI: 0.96-4.54, $P=0.0605$; Figure 3). For two Romanian cases, the histopathological review could not confirm that the sample was from the renal cortex rather than medulla as no glomeruli were present. However, removing these cases from the regression did not substantially change the result $(\mathrm{OR}=2.18$, 95\% CI: 0.98-4.84, $P=0.0560$ ). Excluding from the analysis the sample with the highest quantity of adducts also led to similar result $(\mathrm{OR}=2.20,95 \% \mathrm{CI}$ : 0.78-6.16), whereas the trend was attenuated when restricting the analysis to the 14 cases with detectable adducts $(\mathrm{OR}=1.57,95 \% \mathrm{CI}$ : 0.45-5.37). Adding potential confounders in the model - namely age, sex, body mass index, history of hypertension and tobacco use, level of fibrosis and inflammation in the renal cortex, and stage and grade of the tumour - also did not change the association (ORs varied from 1.98 to 2.30 ).

None of the 14 cases lived in the BEN area at the time of diagnosis (Figure 1). Among five cases with available lifetime residential history, none ever lived in the BEN area. All five had

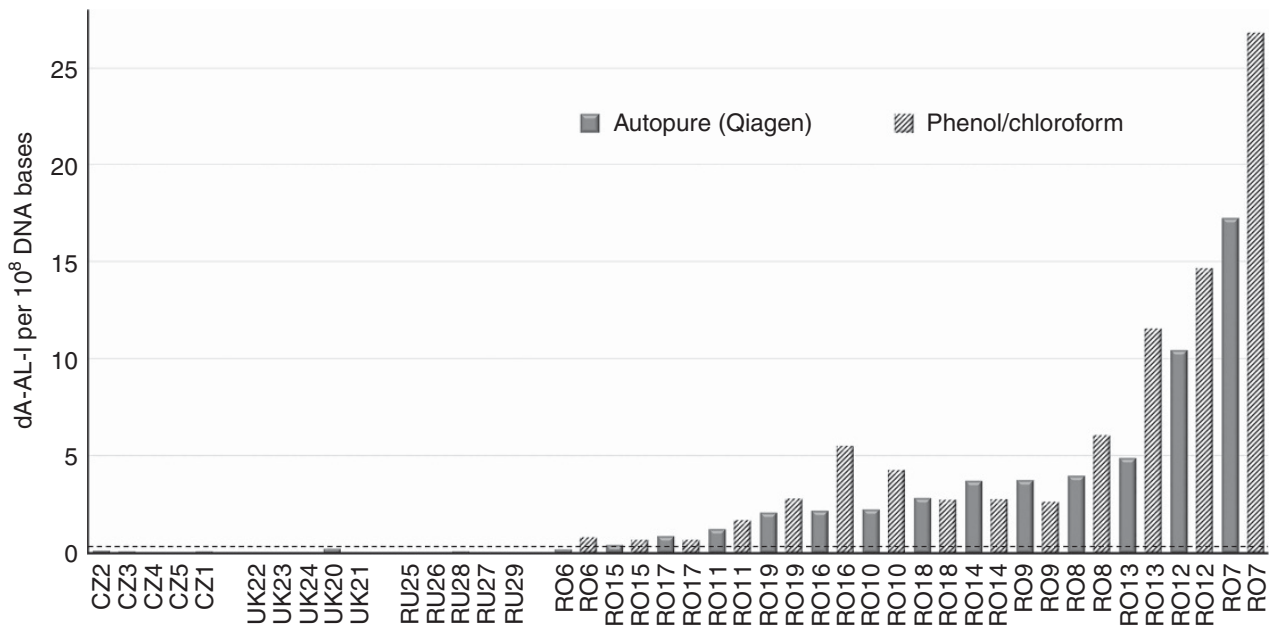

Figure 2. Levels of dA-AL-I adducts in 29 nontumour renal cortex samples from renal cell carcinoma cases of the Czech Republic (CZ), United Kingdom (UK), Russian Federation (RU), and Romania (RO). The dot line indicates the limit of quantification (LOQ) value (0.3 adducts per $10^{8}$ DNA bases). Levels of adducts in Romanian samples were measured in duplicate: on DNA samples extracted with the standard Autopure (Qiagen) protocol, and on DNA samples extracted using a phenol/chloroform protocol. Using the latest samples, cases from Romania harboured dA-AL-I at levels ranging from 0.7 to 27 adducts per $10^{8}$ DNA bases. The levels of adducts in all other cases were below the LOQ value. 


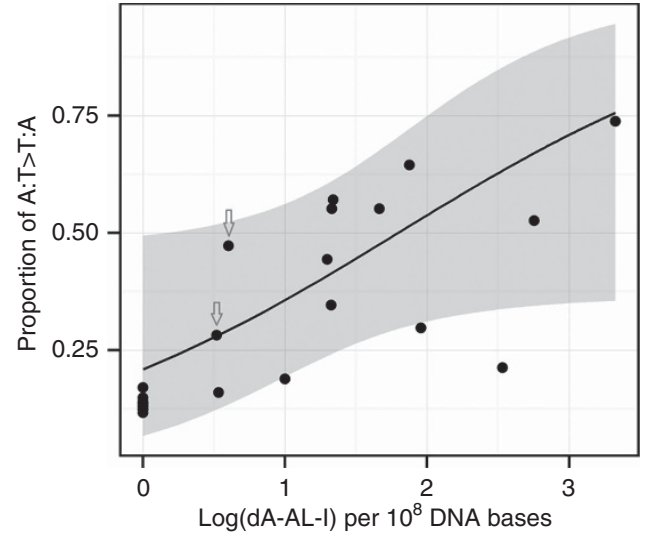

Figure 3. Proportion of $A: T>T: A$ mutations according to the quantity of DNA adducts 7-(deoxyadenosin- $N^{6}$-yl) aristolactam I (dA-AL-I) detected in 14 Romanian and 15 non-Romanian renal cell carcinoma cases. The line corresponds to the binomial model fit to the data (loglinear trend $P=0.0605)$. The grey zone indicates the $95 \%$ confidence interval around proportions predicted by the model. The arrows point to observed data for the two renal parenchyma samples where glomeruli were not present (when removed from the analysis: $P=0.0560$ ). Levels of $d A-A L-I$ were set to zero when below the detection threshold of 0.3 adducts per $10^{8}$ DNA bases. For Romanian subjects, dA-AL-I levels measured in DNA samples isolated using a phenol/chloroform extraction protocol were used for this analysis. Similar results were obtained using levels measured in DNA extracted using a standard Autopure (Qiagen) protocol.

however moved from rural to urban areas. Two cases had lived in counties closed to the BEN area, although both of them were on the lower range of dA-AL-I (0.82 and 2.81 adducts per $10^{8} \mathrm{DNA}$ bases). In addition, counties of the BEN area were not found in any of the 14 personal identification codes.

\section{DISCUSSION}

In all 14 Romanian cases, dA-AL-I was detected at levels similar to those reported in renal cortices of patients with UUTC in Taiwan and the Balkans (Yun et al, 2015). The absence of dA-AL-II was also consistent with previous studies.

The A:T>T:A mutations observed in Romanian tumour samples have yet to be shown to drive the development of cancer, and it remains premature to conclude a causal relationship exists between AA exposure and RCC risk. In particular, although the causal link with UUTC was partly established through the presence of A:T > T:A mutations in the driver gene TP53 (Grollman, 2013), it is unclear whether RCC driver genes are affected as TP53 mutations are rare in RCC and commonly mutated genes did not show the A:T > T:A transversions (Scelo et al, 2014). Whole-exome sequencing of eight RCC cases from endemic AAN regions in Croatia also showed the AA signature in a subset of cases but failed to identify specific driver genes (Jelakovic et al, 2015). Our results leave no doubt that exposure to AA occurs in Romania outside of the described endemic AAN regions. The findings reaffirm previous observations that the $\mathrm{dA}-\mathrm{AL}-\mathrm{I}$ adduct in renal cortex can serve as a biomarker of exposure to AA (Grollman, 2013; Schmeiser et al, 2014). As dA-AL-I is a highly persistent lesion, we could not however determine the timing or the source(s) of exposure. As contamination of industrially produced flour with Aristolochia sp. seeds is unlikely, the use of traditional therapeutic remedies containing the plant should be urgently investigated as potential contributors. The medical use of Aristolochia sp. is allowed by the current Romanian legislation (Gluhovschi et al,
2010), and traditional remedies have been gaining popularity with the increase of alternative/homeopathic medicine shops; studies should be planned to investigate the consumption in the population, and compare levels between kidney cancer cases, chronic kidney disease cases, and healthy individuals. If AA is a cause of RCC, public awareness of AA will have implications for RCC prevention in other parts of the world where herbal remedies containing AA is prevalent.

\section{ACKNOWLEDGEMENTS}

We thank David Zaridze and Anush Moukeria (Russian NN Blokhin Cancer Research Centre, Moscow, Russian Federation), Ivana Holcatova (First Faculty of Medicine, Charles University in Prague, Prague, Czech Republic) and Antonin Brisuda (University Hospital Motol, Prague, Czech Republic), Lenka Foretova and Marie Navratilova (Masaryk Memorial Cancer Institute and MF MU, Brno, Czech Republic) for the collection of biospecimens and data from the Russian Federation and the Czech Republic; Christine Carreira (International Agency for Research on Cancer, Lyon, France) for processing renal biosamples in preparation for pathological review and DNA extractions; Cyrille Cuenin (International Agency for Research on Cancer, Lyon, France) for his technical support in DNA extractions; David Muller (International Agency for Research on Cancer, Lyon, France) for statistical support; Members of the CAGEKID consortium (http:// www.cng.fr/cagekid/; PMID: 25351205) for their contribution to generating DNA sequencing data and enlightening discussions on the initial results. This research was funded in part by the National Institute of Environmental Health Sciences R01ES019564 (to RJT); the National Cancer Institute Cancer Center Support Grant CA77598 (to RJT); the European Union FP7 241669 (the CAGEKID project, to GML); and the National Cancer Institute U01CA155309 (to GS).

\section{CONFLICT OF INTEREST}

The authors declare no conflict of interest.

\section{AUTHOR CONTRIBUTIONS}

BHY and RJT: mass spectrometry experimental design and implementation of experiments, analysis and interpretation of data, and manuscript drafting; $\mathrm{PB}$ : interpretation of data; DM, VJ and REB: biosample collection and interpretation of data; $\mathrm{PH}$ : pathological review of biosamples and interpretation of data; $\mathrm{HB}$ and PC: biosample processing and interpretation of data; M-TB: DNA sequencing and interpretation of data; LL: DNA sequencing data processing and interpretation of data; GML: DNA sequencing experimental design and analysis and interpretation of data; GS: experimental designs, analysis and interpretation of data, and manuscript drafting.

\section{REFERENCES}

Attaluri S, Bonala RR, Yang IY, Lukin MA, Wen Y, Grollman AP, Moriya M, Iden CR, Johnson F (2010) DNA adducts of aristolochic acid II: total synthesis and site-specific mutagenesis studies in mammalian cells. Nucleic Acids Res 38(1): 339-352.

Chen CH, Dickman KG, Moriya M, Zavadil J, Sidorenko VS, Edwards KL, Gnatenko DV, Wu L, Turesky RJ, Wu XR, Pu YS, Grollman AP (2012) Aristolochic acid-associated urothelial cancer in Taiwan. Proc Natl Acad Sci USA 109(21): 8241-8246. 
Debelle FD, Vanherweghem JL, Nortier JL (2008) Aristolochic acid nephropathy: a worldwide problem. Kidney Int 74(2): 158-169.

Gluhovschi G, Margineanu F, Kaycsa A, Velciov S, Gluhovschi C, Bob F, Petrica L, Bozdog G, Dumitru S, Olosz E, Modalca M (2010) Therapeutic remedies based on Aristolochia clematitis in the main foci of Balkan endemic nephropathy in Romania. Nephron Clin Pract 116(1): c36-c46.

Grollman AP (2013) Aristolochic acid nephropathy: Harbinger of a global iatrogenic disease. Environ Mol Mutagen 54(1): 1-7.

Grollman AP, Shibutani S, Moriya M, Miller F, Wu L, Moll U, Suzuki N, Fernandes A, Rosenquist T, Medverec Z, Jakovina K, Brdar B, Slade N, Turesky RJ, Goodenough AK, Rieger R, Vukelic M, Jelakovic B (2007) Aristolochic acid and the etiology of endemic (Balkan) nephropathy. Proc Natl Acad Sci USA 104(29): 12129-12134.

Hoang ML, Chen CH, Sidorenko VS, He J, Dickman KG, Yun BH, Moriya M, Niknafs N, Douville C, Karchin R, Turesky RJ, Pu YS, Vogelstein B, Papadopoulos N, Grollman AP, Kinzler KW, Rosenquist TA (2013) Mutational signature of aristolochic acid exposure as revealed by wholeexome sequencing. Sci Transl Med 5(197): 197ra102.

Jelakovic B, Castells X, Tomic K, Ardin M, Karanovic S, Zavadil J (2015) Renal cell carcinomas of chronic kidney disease patients harbor the mutational signature of carcinogenic aristolochic acid. Int J Cancer 136(12): 2967-2972.

Poon SL, Pang ST, McPherson JR, Yu W, Huang KK, Guan P, Weng WH, Siew EY, Liu Y, Heng HL, Chong SC, Gan A, Tay ST, Lim WK, Cutcutache I, Huang D, Ler LD, Nairismagi ML, Lee MH, Chang YH, Yu KJ, Chan-On W, Li BK, Yuan YF, Qian CN, Ng KF, Wu CF, Hsu CL, Bunte RM, Stratton MR, Futreal PA, Sung WK, Chuang CK, Ong CK, Rozen SG, Tan P, Teh BT (2013) Genome-wide mutational signatures of aristolochic Acid and its application as a screening tool. Sci Transl Med 5(197): 197ra101.

Scelo G, Riazalhosseini Y, Greger L, Letourneau L, Gonzalez-Porta M, Wozniak MB, Bourgey M, Harnden P, Egevad L, Jackson SM, Karimzadeh M, Arseneault M, Lepage P, How-Kit A, Daunay A, Renault V, Blanche H, Tubacher E, Sehmoun J, Viksna J, Celms E, Opmanis M, Zarins A, Vasudev NS, Seywright M, Abedi-Ardekani B, Carreira C, Selby PJ, Cartledge JJ, Byrnes G, Zavadil J, Su J, Holcatova I, Brisuda A, Zaridze D, Moukeria A, Foretova L, Navratilova M, Mates D, Jinga V, Artemov A, Nedoluzhko A, Mazur A, Rastorguev S, Boulygina E, Heath S, Gut M, Bihoreau MT, Lechner D, Foglio M, Gut IG, Skryabin K, Prokhortchouk E,
Cambon-Thomsen A, Rung J, Bourque G, Brennan P, Tost J, Banks RE, Brazma A, Lathrop GM (2014) Variation in genomic landscape of clear cell renal cell carcinoma across Europe. Nat Commun 5: 5135.

Schmeiser HH, Nortier JL, Singh R, da Costa GG, Sennesael J, Cassuto-Viguier E, Ambrosetti D, Rorive S, Pozdzik A, Phillips DH, Stiborova M, Arlt VM (2014) Exceptionally long-term persistence of DNA adducts formed by carcinogenic aristolochic acid I in renal tissue from patients with aristolochic acid nephropathy. Int J Cancer 135(2): 502-507.

Sidorenko VS, Yeo JE, Bonala RR, Johnson F, Schärer OD, Grollman AP (2012) Lack of recognition by global-genome nucleotide excision repair accounts for the high mutagenicity and persistence of aristolactam-DNA adducts. Nucleic Acids Res 40(6): 2494-2505.

Stefanovic V, Polenakovic M (2009) Fifty years of research in Balkan endemic nephropathy: where are we now? Nephron Clin Pract 112(2): c51-c56.

Yun BH, Sidorenko VS, Rosenquist TA, Dickman KG, Grollman AP, Turesky RJ (2015) New approaches for biomonitoring exposure to the human carcinogen aristolochic acid. Toxicol Res 4: 763-776.

Yun BH, Rosenquist TA, Nikolic J, Dragicevic D, Tomic K, Jelakovic B, Dickman KG, Grollman AP, Turesky RJ (2013) Human formalin-fixed paraffin-embedded tissues: an untapped specimen for biomonitoring of carcinogen DNA adducts by mass spectrometry. Anal Chem 85(9): 4251-4258.

Yun BH, Rosenquist TA, Sidorenko V, Iden CR, Chen CH, Pu YS, Bonala R, Johnson F, Dickman KG, Grollman AP, Turesky RJ (2012) Biomonitoring of aristolactam-DNA adducts in human tissues using ultra-performance liquid chromatography/ion-trap mass spectrometry. Chem Res Toxicol 25(5): 1119-1131.

Yun BH, Yao L, Jelakovic B, Nikolic J, Dickman KG, Grollman AP, Rosenquist TA, Turesky RJ (2014) Formalin-fixed paraffin-embedded tissue as a source for quantitation of carcinogen DNA adducts: aristolochic acid as a prototype carcinogen. Carcinogenesis 35(9): 2055-2061.

cc)(1)(2) This work is licensed under the Creative Commons BY NC SA Attribution-Non-Commercial-Share Alike 4.0 International License. To view a copy of this license, visit http:// creativecommons.org/licenses/by-nc-sa/4.0/

Supplementary Information accompanies this paper on British Journal of Cancer website (http://www.nature.com/bjc) 